\title{
Predictive Accuracy of Mandibular Ramus Flexure as a Morphologic Indicator of Sex Dimorphism in Jordanians
}

\author{
Exactitud Predictiva de la Flexura de la Rama Mandibular \\ como Indicador Morfológico de Dimorfismo Sexual en Jordanos
}

Badran, D. H."; Othman, D. A.**; Thnaibat, H. W.** \& Amin W. M.***

BADRAN, D. H; OTHMAN, D. A; THNAIBAT, H. W \& AMIN, W. M. Predictive accuracy of mandibular ramus flexure as a morphologic indicator of sex dimorphism in Jordanians. Int. J. Morphol., 33(4):1248-1254, 2015.

SUMMARY: The present study investigated the validity of mandibular ramus flexure in sex differentiation among young Jordanian adults using Orthopantomographic images in a double blind study. A normative sample comprised of 419 images was selected, of which 126 belonged to male patients and 293 images to females. The exclusion criteria used in the selection involved excluding images that showed marked loss of mandibular molars, over erupted, tilted, anomalous molars and teeth or mandibles associated with pathology. Each image was examined for the presence of a flexure on the posterior margin of the ramus at the occlusal plane. The posterior margin of the ramus was carefully traced graphically and the occlusal plane level was delineated as guided by the height of cusp tips at the occlusal surfaces of the mandibular molars. The ramus flexure was more accurately diagnostic for females (94.6\%), than for males (47.6\%); this gave rise to an overall diagnostic accuracy of 70.9\% which is far below the reported 90.6-99.0\% by Loth \& Henneberg. Our results, however, agreed with some reported findings of other researchers. In conclusion, ramus flexure provides a moderately acceptable predictive accuracy and could be considered as a supplementary rather than a definitive mean of sex determination. In sexing unknown skeletal remains, it is necessary to employ as many methods or traits as possible instead of relying on one morphological trait.

KEY WORDS: Sex dimorphism; Ramus flexure; Morphologic trait; Predictive accuracy; Forensic fossils; Skeletal remains.

\section{INTRODUCTION}

Skeletal remains represent an important source of identification. It has contributed in the evolution of forensic medicine, osteology and physical anthropology in which sex, age; stature and ethnic origin can be detected from the skeletal remains, though sex determination is considered the most challenging (Balci et al., 2005). Pelvis and mandible reflect anatomical differences between male and female, therefore they were used in many previous studies. These studies centered on morphological differences of the skeleton that arise from genetically sex-linked growth and development, allow better assessment of the sexes (Krogman \& Iscan, 1986; Novotny et al., 1993). The mandible was used in most studies since it is one of the most durable bones. There have been many publications dealing with sexual differentiation according to morphological traits of the mandible. Loth \& Henneberg (1996, 1997, 1998, 2000) were of the early publications described a flexure in the posterior margin of the ramus that was present in male, but absent in female mandibles, and used the flexure in sex determination. They claimed sexing accuracy ranging from $90.6 \%$ to $99 \%$ that the ramus is flexed in males at the occlusal plane whereas in females it is either straight or flexed near the neck of condyle process or in association with gonial prominence. Donnelly et al. (1998) and Haun (2000) reported that the association between ramus flexure and sex was weak; and that Loth \& Henneberg method was based on a trait which, they believed, cannot be reliably or consistently identified. Hill (2000) also evaluated Loth \& Henneberg's sex identification method and found it to be of a low overall accuracy, an invalid scoring system and of a high intraobserver error. It was concluded, therefore, that the mandibular ramus flexure was an unreliable technique for estimation of sex. Balci et al., reported that marked differences existed between sexes in the predictive and accuracy of Loth and Henneberg sex identifier which sexed males are more reliably than females. Oettlé et al. (2005)

\footnotetext{
* Associate Professor, Department of Anatomy and Histology, Faculty of Medicine, The University of Jordan, Amman, Jordan.

** Clinical Intern and Research Fellow, Department of Clinical Dentistry, Jordan University Hospital, Amman, Jordan.

**** Professor of Prosthodontics and Biomaterials, Faculty of Dentistry, The University of Jordan, Amman, Jordan.
} 
observed that variation in mandibular ramus morphology have a biomechanical rather than hormonal origin. They reported that although the ramus flexure seemed to be greater and more constant in males, the overlap between the shapes of male and female rami was too great to make the ramus flexure method a usable means of sex determination. Suazo et al. (2008) reported that about two-thirds of the OPT images of the female subjects they studied were correctly sexed, whereas the prediction accuracy was less than $50 \%$ for men. Tamer (2012) evaluated the sex diagnostic power of the mandibular flexure method on 100 OPT images and revealed an overall accuracy of $83 \%$. Shivaprakash \& Vijay Kumar (2014) carried out a study on a sample of almost similar size (104 subjects) and reported an overall predictive accuracy of $76 \%$.

Those were much lower than the success rates reported by Loth \& Henneberg, which raised doubts on the predictive accuracy and reliability of mandibular flexure as a morphological indicator of sex. Authors of those studies pointed out that using this sex dimorphic predictor does not attain a high confidence level, and they commented that it should, therefore, be coupled with other indicators of sex dimorphism.

The aim of the present study was to investigate the validity of mandibular ramus flexure in sex differentiation among Jordanian young adults using panoramic images in a double blind study.

\section{MATERIAL AND METHOD}

The present investigation was conducted on a representative sample consisting of 419 randomly selected orthopantomographic images (OPT) of dentate young adult patients of an average age of 19.3 years, that ranged between 13-26 years, who attended clinics of the dental department of the Jordan University Hospital (JUH) during the period between June 1st and August $30^{\text {th }}$, 2013. Of the total sample, 126 were males whose average age was 19.16 years and 293 were females of an average age of 19.32 years. The exclusion criteria used in selecting the test sample involved excluding images that showed excessive loss of mandibular posterior teeth, over erupted, tilted, anomalous molars and teeth or mandibles associated with pathology.

Prior to conducting the investigation, and in compliance with the policy of the Clinical Research Authority at the JUH, signed written informed consents were obtained from all the subjects selected for the study. All subjects were made aware that their OPT images were included in the investigation. The experimental protocol was examined and approved by the Ethics Committee and was, therefore, performed in accordance with the ethical standards laid down in the 1964 Declaration of Helsinki (WMA, Helsinki, 1964).

The Dental department at the JUH uses a computerized Kodak Dental Imaging system (Kodak laboratories, Rochester, NY, USA) the software of which was designed to processOPT images and saves them as "Joint Photographic Experts Group"(JPEG) file format. Each image was given a code that did not indicate patient's sex.

The OPT images were examined and analyzed according to the guidelines described by Loth \& Henneberg (1996). Each OPT image was examined, firstly, for a possible presence of a flexure at the posterior margin of the ramus, and if present, the height of flexure was carefully marked. Secondly, the occlusal plane level was delineated as guided by the height of cusp tips at the occlusal surfaces of the mandibular molars. A decision was made whether or not the ramus flexure coincided with the occlusal plane level. Examination of the OPT images and careful digitization of their landmarks was facilitated by graphical tracing of the posterior margin of the ramus; the deepest flexure point on the curving ramus margin was traced on both sides. A tangent line was drawn passing through two points, the first was the most prominent point on the posterior profile of the condylar head and the second point marked the maximum convexity of the posterior margin of the mandibular angle. The height of the occlusal plane was marked by a line passing through the most prominent cusp tips of the first and second mandibular molars. Third molars, if present, were not used in the determination of the occlusal plane height (Fig. 1).

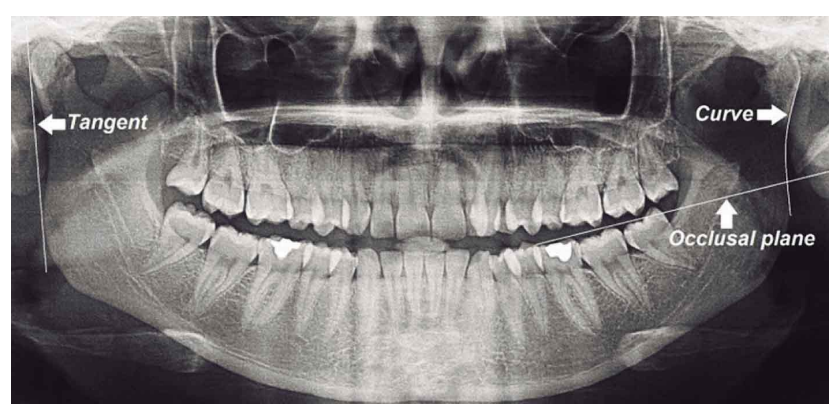

Fig. 1. An OPT image illustrating a tangent line of the mandibular condyle and angle; a line marking the occlusal plane and a curve marking flexure of the posterior margin of the mandibular ramus.

The OPT images of the entire sample were scored according to Loth \& Henneberg (1996) method. Score points were given for the left and right rami of each image, then added together and the total score was used in sex prediction. 
A score of (+1) was given when a posterior margin flexure of one side ramus coincided with the occlusal plane height at that side; a score of (-1) was given to a straight posterior margin ramus and to a ramus in which the flexure of its posterior margin did not coincide with the height of the occlusal plane but located either above or below the occlusal plane level, i. e., near the condyle or the mandibular angle; score (0) was given to a ramus the posterior margin of which was neither flexed nor straight.

When scores of both rami were added, a total score of (+2) was assigned to the OPT in which both rami had a flexure coincided with the occlusal plane; a score of $(-2)$ was given when both rami had straight posterior margins or to rami the flexure of which did not coincide with the occlusal plane but were high near the condyle or low near the mandibular angle; a total score of $(+1)$ was given when one ramus was flexed at occlusal level and the other was indeterminate; a total score of (0) was assigned to the OPT in which either both rami were indeterminate or one ramus was flexed at the occlusal level and the other was straight; a total score of (-1) was given to the OPT in which one ramus was straight while the other was indeterminate. OPT images of total scores of $(0,+1,+2)$ indicated male subjects, whereas images of total sores of $(-1,-2)$ indicated female subjects (Figs. 2-4).

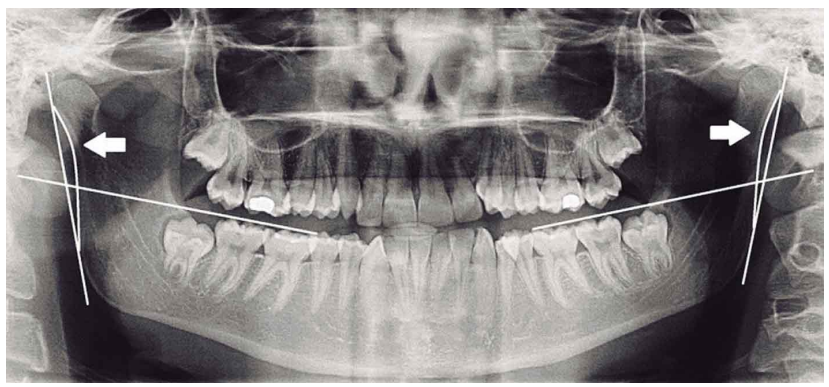

Fig. 2. An OPT image of an adult female, note that deepest flexure point on both rami indicated by the arrows located near the condyle, given a score of $(-1)$ for each ramus and a total score of $(-2)$.

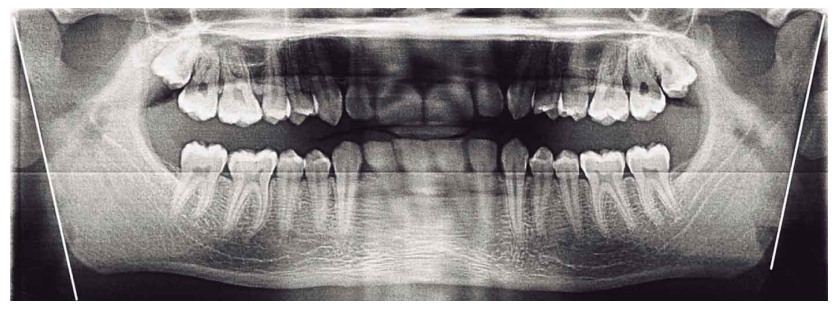

Fig. 3. An OPT image of an adult female, note the straight posterior margins of both rami with no flexure, given a score of $(-1)$ for each ramus and a total score of (-2).

Examination of OPT images was carried out by two examiners, each used a computer of a high resolution screen.

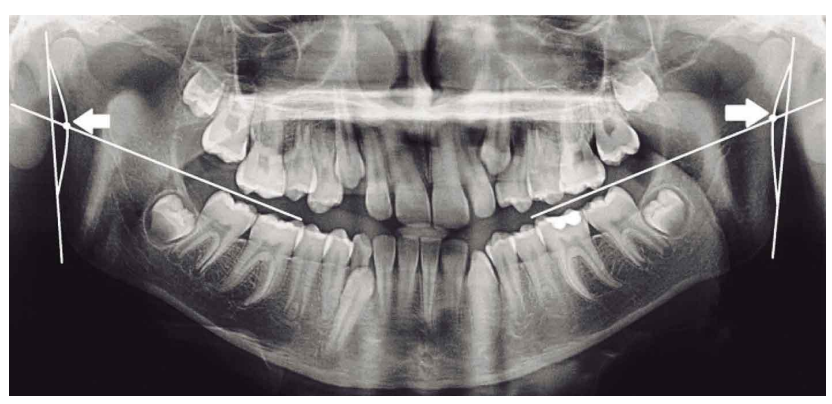

Fig. 4. An OPT image of an adult male, note that the deepest flexure point on both rami coincides with the level the occlusal plane, as indicated by the arrow, given a score of $(+1)$ for each ramus and a total of $(+2)$.

Prior to conducting the examination of the entire sample, the two examiners (D.A.O and H. W.Th) were calibrated by the third investigator (W.M.A) in relation to the trait's morphology criteria required for prediction of subject's sex. The calibration procedure was performed in order to eliminate inter-examiner and intra-examiner variations. The procedure consisted of series of double blind tests in which the examiners tested different samples at the same time and each examiner tested the same sample at different times. In all test series, the examiners were unaware of the sex of the subjects whose OPT images were being examined. The data sets of the calibration tests and the results of examination of the entire sample were statistically analyzed using the appropriate statistical tests.

Statistical treatment. The results of the calibration test of the two examiners were statistically analyzed using "concordance" test. A kappa value of 0.5 indicating a moderate agreement of results of the examiners was considered the minimum acceptable value in this investigation. The examination results of the entire sample were analyzed using SPSS version-21 (Statistical Package for Social Studies; SPSS Ltd, Fountain Valley, CA 92708 USA); the "Chi-squared test," of the package, was employed at a probability level of $\mathrm{p}<0.01$, indicating significant differences would be evaluated at $99 \%$ level of confidence.

\section{RESULTS}

The inter-examiner variation of sex prediction was assessed in a try run on 60 randomly selected OPT images, of which 44 images were Females' OPTs and 16 belonged to male subjects. The two observers individually examined the OPT images, the sex of which was unknown to the observers. The results of the inter-examiners concordance demonstrated a substantial indicator, with a kappa value of 0.664 (Table I). 
Table I. Distribution of sex identification by observer.

\begin{tabular}{llccc}
\hline \multirow{3}{*}{ First Examiner } & & Females & Males & Accuracy (\%) \\
\cline { 2 - 5 } Second Examiner & Females & 40 & 2 & $95.2 \%$ \\
& Males & 4 & 14 & $77.8 \%$ \\
& Females & 36 & 3 & $92.3 \%$ \\
& Males & 8 & 13 & $61.9 \%$
\end{tabular}

Inter-examiner concordance indicated a substantial agreement of the examiners results: kappa $=0.664$

The intra-observer concordance test was carried out on the same OPT images. Double-blind tests performed by the observers, each examined the same sample at two different times separated by one week period. Table II, presents results of an intra-observer examination which showed that $86.1 \%(85.4-86.7 \%)$ of the OPT images of females were accurately identified, whereas the accuracy in identifying male OPTs was less, which only showed $70.9 \%(75.0-66.7 \%)$. The concordance test demonstrated a moderate indicator, with a kappa value of 0.546 (Table II).

Table II. Intra-observer predictive accuracy of ramus flexure as a sex identifier among males and females.

\begin{tabular}{llccc}
\hline \multirow{2}{*}{$\begin{array}{l}\text { First Observer, first } \\
\text { time }\end{array}$} & Females & Males & Accuracy (\%) \\
\cline { 2 - 5 } Same Ob server, one & Males & 41 & 7 & $85.4 \%$ \\
week later & 3 & 9 & $75.0 \%$ \\
& Males & 39 & 6 & $86.7 \%$ \\
& Intra-examiner concordance indicated a moderate \\
& agreement of results: kappa $=0.546$ \\
\hline
\end{tabular}

It is noteworthy that neither a -1 nor $\mathrm{a}+1$ total score was observed in the tested sample. The subjects were clearly distributed among total scores of $-2,0$, and +2 only (Table III).

Table III. Distribution of ramus shape scores in adult Jordanians.

\begin{tabular}{lc}
\hline Score $\left(^{*}\right)$ & Percent (\%) of Total \\
\hline-2 & $78.1 \%$ \\
-1 & 0 \\
0 & $17.1 \%$ \\
+1 & 0 \\
+2 & $4.8 \%$ \\
\hline
\end{tabular}

(*) $+2=$ both rami flexed; $+1=$ one ramus flexed, the other indeterminate; $0=$ either both rami indeterminate or one flexed and the other straight; $-1=$ one ramus flexed, the other indeterminate; $-2=$ both rami straight.

The number of the observed OPT images that scored -2 and were counted as females was only 17 images less than the, 293 OPTs of females, originally included in the samples (Fig. 6). This small difference was found to be statistically insignificant (Chi-squared "X2" $=0.986$ at $\mathrm{p}>0.411)$. On the other hand, the number of correctly predicted male OPT images was less than half that initially present in the sample (Fig. $6)$. The difference, 60 out of 126 , was statistically significant (Chi-squared "X2" $=34.6$ at $\mathrm{p}<0.001$ ).

The results of the second observer were comparable with those of the first. The accuracy levels attained by the second observer were $94.7 \%(92.2-97.2 \%)$ for female subjects and $66.4 \%(64.7-68.1 \%)$ for males.

The OPT images of the entire sample were examined, alternately, by the observers. Sex prediction of the subjects was noted following the method suggested by Loth \& Henneberg (1996). Distribution of subjects and their predicted sex, indicated by the shape of their mandibular ramus, is presented in Table III and Figure 5. Those individuals whose OPT images revealed total scores of -1 and -2 of both rami were classified as female subjects, and those whose rami yielded added scores of $0,+1$, and +2 were counted as males.

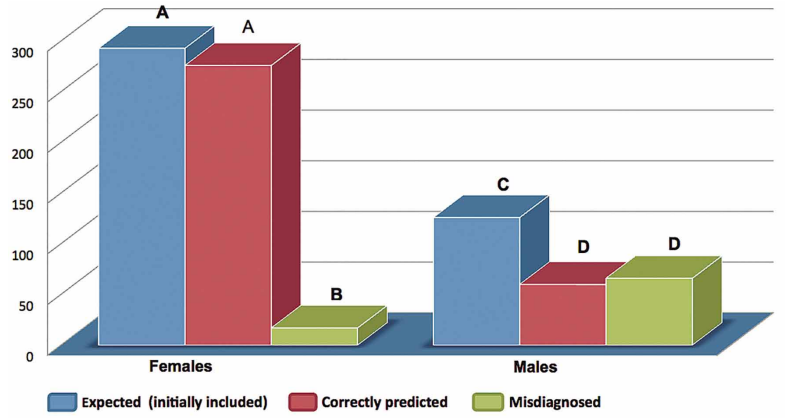

Fig. 6. Number and sex of subjects initially included in the sample, those whose sex correctly predicted by the observer and subjects of misdiagnosed sex. Different alphabets denote statistically significant differences $\mathrm{p}<0.001$.

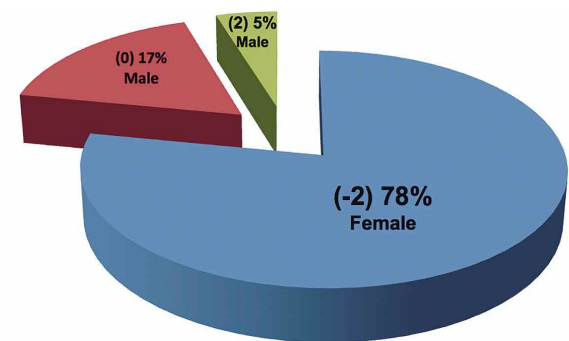

Fig. 5. Distribution of predicted sex and its percentage, indicated by ramus shape.
-2 Both rami straight 00 either both rami indeterminate or one flexed and the other straight +2 Both rami flexed
The results presented in Table III and Figures 5 and 6 demonstrated that when employing Loth \& Henneberg (1996) scoring method for sex identification of the investigated subjects, the ramus flexure was more accurately diagnostic for females $(94.6 \%)$, but the accuracy for male identification (47.6\%) was significantly inferior (Chi-squared X2 $=36.88, \mathrm{p}<0.001$ ) to that for females; this gave rise to an overall diagnostic accuracy of $70.9 \%$. 


\section{DISCUSSION}

Since the introduction in 1996 by Loth \& Henneberg of the idea and method of using mandibular ramus flexure as a morphologic trait for identification of sex, there have been a number of studies in the literature that reported critical appraisals of the method. In addition to its advocates (Loth \& Henneberg, 1996), proponents of ramus flexure trait such as Saini et al. (2011) reported positive critiques in its support, whereas opponents of this method, challenged its validity and predictive accuracy (Koski et al., 1996; Oettlé et al., 2005; Hu et al., 2006). Moreover, researchers haven't been in accord with the predictive sensitivity of ramus flexure for the two sexes. Some researchers believed that the method was of a higher predictive accuracy for males than for females (Donnelly et al.; Haun; Hill; Kemkes-Grottenthaler et al., 2002; Balci et al.; Oettlé et al.; Shivaprakash \& Vijaykumar), whereas others thought that the method was of more diagnostic sensitivity to females (Suazo et al.; Tamer, 2012).

To this end, the lack of consensus among researchers which reflected differences in their reported findings and theoretical positions has necessitated that the present study should be planned in such a way that it would avoid subjectivity of opinion and not allow for a personal bias. Accordingly, the present study was designed, from the outset, to be a blind investigation employing two observers who should be calibrated and whose test results should reflect a clearly acceptable degree of agreement.

The controversy among researchers regarding the predictive accuracy of ramus flexure method has, obviously, resulted from differences in the nature of the samples employed by different investigators. Some test samples comprised of what was referred to as "pathological" cases, such as leprosy and syphilis that cause significant deformation of the skull and mandible. Paget's disease and acromegaly were linked to enlargement, thickening, and masculinization in females (Ortner \& Putschar, 1981; Daegling, 1993; Loth \& Henneberg, 1996). Some samples contained mandibles with excessive posterior tooth loss that, inevitably, led to erroneous delineation of the occlusal plane and resulted in a misdiagnosed sex. Loss of posterior teeth in the maxilla or mandible not only leads to consequential shifting, drifting, overeruption and rotation of neighboring and opposing teeth, but it also alters the pattern of the masticatory muscle action and their effect on the eating habit and distribution of the occlusal load which, in turn, induces an irregular bone resorption and may interfere with remodeling and reshaping of bone. Some other samples contained fragmented mandibles such as in forensic cases and in fossils of unknown skeletal remains in which cases a precise location of ramus flexure and an accurate delineation of the occlusal plane may not be possible. Owing to these reasons, some researchers questioned the prediction potential of ramus flexure when applied in "pathological" samples and suggested caution should be practiced when this trait was employed in such cases (Haun). Other researchers were categorically against using this trait and emphasized that ramus flexure method doesn't provide a definite mean of sex determination of fragmentary forensic and fossil remains (Oettlé et al.). It was for this reason; the randomly selected sample in the present study was subjected to very strict exclusion criteria whereby only those OPT images that belonged to a normative sample were investigated. The fact that all "pathological" cases and OPT images of fragmented mandibles caused by trauma were excluded, could explain why the distribution of subjects in this study were solely among total scores of $-2,0$, and +2 ; and there was a total absence of +1 and -1 scores. The latter two scores $(-1$ and +1$)$ were reported as predominantly associated with "pathological" cases characterized by posterior tooth loss or having severe dental attrition (Loth \& Henneberg 1996; Haun; Balci et al.). Since the objective of this investigation was to evaluate the validity and efficacy of ramus flexure as a sex predictor, it was imperative to employ a strictly normative sample and exclude all "pathological" and trauma cases that may confuse diagnosis and reduce predictive accuracy of ramus flexure trait.

The results of the present study showed an overall predictive accuracy of $70.9 \%$; this was substantially lower than those previously reported by Loth \& Henneberg (1996), Indrayana et al. (1998), Hill, Haun, Balci et al., Saini et al., Tamer and Shivaprakash \& Vijaykumar (See Fig. 7); but was higher than the overall predictive accuracy reported by Donnelly et al., Kemkes-Grottenthaler et al., Oettlé et al. and Suazo et al. The differences among researchers in the reported value of the overall predictive accuracy of ramus flexure could be ascribes, firstly, as mentioned above, to the differences in the nature of the employed samples. Most researchers employed and worked on samples that comprised 'pathological' cases which increased the risk of misdiagnosis and compromised the accuracy of sex prediction. Secondly, it may also be attributed to the subjective assumption of the exact location of flexure of the posterior margin of mandibular ramus.

It is clearly obvious that the strict exclusion criteria employed in selecting the test sample in the present study, and the use of graphical tracing of the posterior margin of the mandibular ramus have helped eliminate all guesswork and yielded more precise and accurate outcomes that empowered the diagnostic faculty of our approach.

The results of this study demonstrated that despite the fact that the female subjects were of the same age as the males 


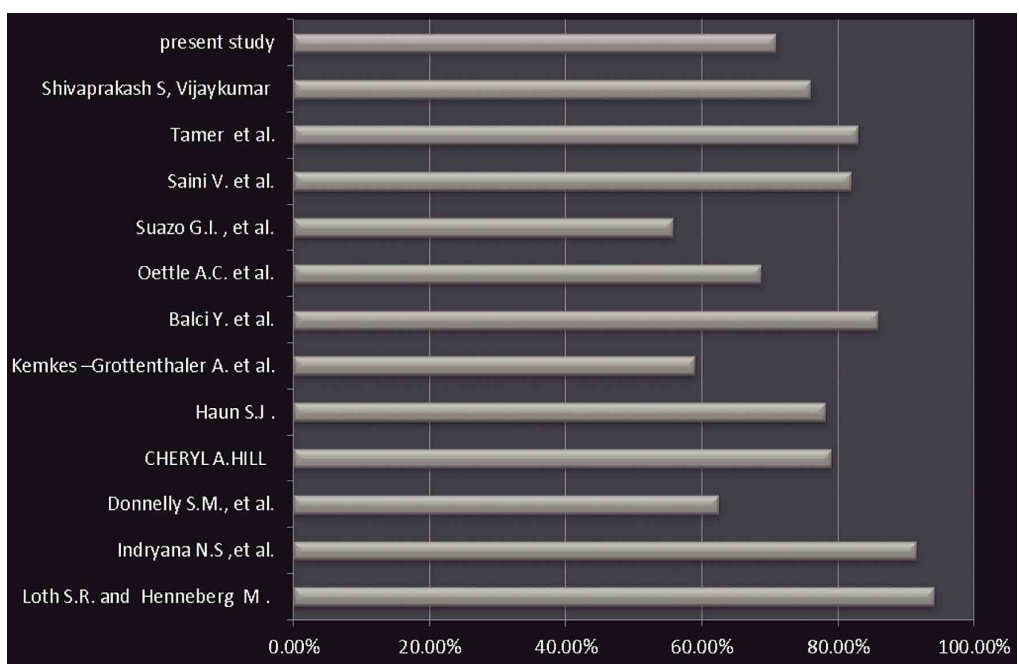

Fig. 7. Bar chart demonstrating a comparison of the overall predictive accuracy of ramus flexure as sex indicator among adult Jordanians (top bar) and similar reported studies.

(mean age of females was 19.32 years and that of males was 19.15 years), the evaluated sex prediction method was more diagnostic for females. These results support the findings reported by Suazo et al. who conducted an investigation on a Chilean sample whose mean age was 21.13 years, and the findings of Tamer, who studied an Egyptian sample of an average age of 42.25 years. These two studies also found that the ramus flexure method was more diagnostic for females than for male subjects. It is noteworthy, that the mean age of the investigated samples in those two studies as well as that of the present study was post puberty young adulthood age, and the fact that females reach puberty earlier than males could explain why the sex predictor of sexual dimorphism under evaluation was more diagnostic for females. In other words, the degree of expression of the morphologic trait being evaluated could well be sex-linked and controlled by the influence of hormonal changes. It is known that changes in the shape of the mandible affected by the forces of muscles, particularly the elevator muscles, which is determinant in the modeling of the mandibular ramus, are at their peak in young adults (Koski). The time around which the growth at the temporomandibular joint ceases. Prior to that age and throughout the period of active growth, the expression of the shape of mandible including ramus flexure is in response to hormonal influences and is governed, in both sexes, by the forces exerted by the masticatory muscles. It was stated that "the high level of dimorphism in ramus may arise in response to sex-specific hormones in susceptible skeletal sites" (Loth \& Henneberg, 1996). As is the case with most sites of the skeleton, sex-based variation in growth rates and pattern is also reflected in the mandible, whereby the major hormonal influences triggered to initiate sexual maturation at puberty targets receptors in the mandible (Loth \& Henneberg, 2001). These, in turn, incur significant sex differences in mandibular shape and dimensions influenced by the configuration of the muscles of mastication. The creation of the flexure is likely to result from a change in the size, strength or angulation of the muscles of mastication, specially the masseter and the medial pterygoid muscles, which attach just below the level of flexure on the ramus. In males, where rugosity of the medial pterygoid muscles attachment is noticeably more pronounced than that of the masseter, the ramus appears much more vertical. The temporalis and the lateral pterygoid muscles attach well above the flexure (Loth \& Henneberg, 1996). The influence of muscles in molding the mandibular ramus is expected to come to a complete halt at the cessation of growth at the temporomandibular joint around the age of young adulthood. Further musculoskeletal maturation at older ages is not expected to incur any significant change in the shape of mandibular ramus flexure in males as well as females, but the mandible in both sexes retain its pubertal shape in older ages. This fact was substantiated by the comparison made between the results of the present study and those reported by Tamer, who investigated an Egyptian sample whose average age was more than double that of our sample, albeit both studies indicated superiority of the predictive accuracy of female subjects compared to that of males.

Several researchers attributed the differences in their findings regarding the degree of trait expression to population specific factors influenced by environmental functional variables such as chewing habits and food type. The present study did not confirm that justification, but showed that comparable results could arise from studies conducted on samples of different populations living in countries that are geographically distant from each other, as was the case that arisen by a comparison between our findings and those reported by Suazo et al. Even though the latter investigation was carried out on a Chilean sample of the same average age as that of our sample and despite differences in food type and eating habits between the two peoples, both studies demonstrated superiority of the predictive accuracy of females over that of males. The Chilean researchers' results too refuted the extremely high overall as well as males' predictive accuracy of ramus flexure trait reported by Loth \& Henneberg (1996).

CONCLUSION. Mandibular ramus flexure may be useful in sex identification; our results showed that it provides a moderately acceptable overall predictive accuracy and could be considered as a supplementary rather than a definitive mean of sex determination. In sexing unknown skeletal remains, it is necessary to employ as many methods or traits as possible instead of relying on one morphological trait. 
BADRAN, D. H; OTHMAN, D. A; THNAIBAT, H. W \& AMIN, W. M. Exactitud predictiva de la flexura de la rama mandibular como indicador morfológicos de dimorfismo sexual en jordanos. Int. J. Morphol., 33(4):1248-1254, 2015

RESUMEN: El presente estudio investigó la validez de flexura de la rama mandibular en la diferenciación sexual entre adultos jóvenes jordanos utilizando imágenes de ortopantomografías, en un estudio doble ciego. Se seleccionó una muestra normativa compuesta de 419 imágenes, de las cuales 126 pertenecían a hombres y 293 a mujeres. Se excluyeron imágenes que mostraron una pérdida marcada de los molares mandibulares, dientes sobre erupcionados o inclinados, molares anómalos y los dientes o mandíbulas con enfermedad. Cada imagen fue examinada para detectar la presencia de un ángulo en el margen posterior de la rama en el plano oclusal. El margen posterior de la rama mandibular fue trazado gráficamente y el plano oclusal se delineó estableciendo como guía la altura de las puntas cuspídeas en las superficies oclusales de los molares mandibulares. La flexura de la rama mandibular fue más precisa en el diagnóstico de las mujeres $(94,6 \%)$ que para los hombres $(47,6 \%)$; con una precisión diagnóstica global del $70,9 \%$, la cual es inferior a la reportada por Loth \& Henneberg entre $90,6-99,0 \%$. Nuestros resultados, concuerdan con algunos hallazgos reportados por otros investigadores. En conclusión, la flexura de la rama mandibular proporciona una exactitud de predicción moderadamente aceptable y podría ser considerada como un complemento en lugar de un medio definitivo de la determinación del sexo. En restos óseos desconocidos, es necesario emplear la mayor cantidad de métodos o rasgos posibles que depender de un solo rasgo morfológico.

PALABRAS CLAVE: Dimorfismo sexual; Flexura de la rama mandibular; Rasgo morfológico; Exactitud predictiva; Fósiles forenses; Restos óseos.

\section{REFERENCES}

Balci, Y.; Yavuz, M. F. \& CaGdir, S. Predictive accuracy of sexing the mandible by ramus flexure. Homo. 55(3):229-37, 2005.

Daegling, D. J. Functional morphology of the human chin. Evol. Anthropol., 1(5):170-7, 1993.

Donnelly, S. M.; Hens, S. M.; Roger, N. L. \& Schneider, K. L. Technical note: a blind test of mandibular ramus flexure as a morphologic indicator of sexual dimorphism in the human skeleton. Am. J. Phys. Anthropol., 107(3):363-6, 1998.

Haun, S. J. Brief communication: a study of the predictive accuracy of mandibular ramus flexure as a singular morphologic indicator of sex in an archaeological sample. Am. J. Phys. Anthropol., 111(3):429-32, 2000 .

Hill, C. A. Technical note: evaluating mandibular ramus flexure as a morphological indicator of sex. Am. J. Phys. Anthropol., 111(4):5737, 2000 .

Hu, K. S.; Koh, K. S.; Han, S. H.; Shin, K. J. \& Kim, H. J. Sex determination using nonmetric characteristics of the mandible in Koreans. J. Forensic Sci., 51(6):1376-82, 2006.

Indrayana, N. S.; Glinka, J. \& Mieke, S. Mandibular ramus flexure in an Indonesian population. Am. J. Phys. Anthropol., 105(1):89-90, 1998.

Kemkes-Grottenthaler, A.; Löbig, F. \& Stock, F. Mandibular ramus flexure and gonial eversion as morphologic indicators of sex. Homo, 53(2):97111, 2002.
Koski, K. Mandibular ramus flexure--indicator of sexual dimorphism? Am. J. Phys. Anthropol., 101(4):545-6, 1996.

Krogman, W. M. \& Iscan, M. Y. The human skeleton in forensic medicine. Springfield, C. C. Thomas Publications, 1986.

Loth, S. R. \& Henneberg, M. Mandibular ramus flexure: a new morphologic indicator of sexual dimorphism in the human skeleton. Am. J. Phys. Anthropol., 99(3):473-85, 1996.

Loth, S. R. \& Henneberg, M. Ramus flexure and symphyseal base shape: sexually dimorphic morphology in the premodern hominid mandible. Am. J. Phys. Anthrop., Suppl. 24:156-7, 1997.

Loth, S. R. \& Henneberg, M. Mandibular ramus flexure is a good indicator of sexual dimorphism. Am. J. Phys. Anthropol., 105(1):91-2, 1998.

Loth, S. R. \& Henneberg, M. Gonial eversion: facial architecture, not sex. Homo, 51:81-9, 2000.

Novotony, V.; Iscan, M. Y. \& Loth, S. R. Morphologic and osteometric assessment of age, sex and race from the skull. In: Iscan, M. Y. \& Helmer, R. P. (Eds.). Forensic analysis of the skull. New York, Willy Liss, 1993. pp.71-88.

Oettlé, A. C.; Pretorius, E. \& Steyn, M. Geometric morphometric analysis of mandibular ramus flexure. Am. J. Phys. Anthropol., 128(3):623-9, 2005.

Ortner, D. J. \& Putschar, W. G. Identification of pathological conditions in human skeletal remains. Washington DC, Smithsonian Institution, 1981.

Shivaprakash, S. \& Vijaykumar, A. G. Sex Determination by Using Mandibular Ramus Posterior Flexure - A Prospective Study. Int. J. Health Sci. Res., 4(1):155-9, 2014.

Saini, V.; Srivastava, R.; Shamal, S. N.; Singh, T. B.; Pandey, A. K. \& Tripathi, S. K. Sex determination using mandibular ramus flexure: a preliminary study on Indian population. J. Forensic Leg. Med., 18(5):208-12, 2011.

Suazo, G. I.; San Pedro, V. J.; Schilling, Q. N.; Celis, C. C.; Hidalgo, R. J. \& Cantin, L. M. Orthopantomographic blind test of mandibular ramus flexure as a morphological indicator of sex in Chilean young adults. Int. J. Morphol., 26(1):89-92, 2008.

Tamer, M. Predictive Accuracy of Mandibular Ramus Flexure as a Morphologic Indicator of Sex among Adult Egyptians. Munich, GRIN Verlag, 2012.

World Medical Association (WMA). Declaration of Helsinki-Ethical Principles for Medical Research Involving Human Subjects. Proceedings of the 18th General Assembly, Helsinki, Finland, 1964.

\section{Correspondence to:}

Darwish Badran

Department of Anatomy and Histology

Faculty of Medicine

University of Jordan

Amman, 11942

JORDAN

Received: 23-04-2015

Accepted: 30-07-2015

Email: dhbadran@ju.edu.jo 